\title{
Desenvolvimento sustentável ou modernização ecológica? Uma análise exploratória
}

\author{
Sustainable development or ecological modernization? an exploratory analysis
}

\section{Luciano Munck* Rafael Borim de Souza**}

\begin{abstract}
Resumo:
Este artigo foi desenvolvido com o intuito principal de investigar qual expressão possui maior densidade teórica para indicar caminhos para operacionalização das premissas de um desenvolvimento sustentável: o próprio desenvolvimento sustentável ou a modernização ecológica? Para tanto foi realizado um ensaio teórico, qualitativo, exploratório e bibliográfico. Percebeu-se que a teoria da modernização ecológica possui um rigor analítico superior ao participado pelo desenvolvimento sustentável, possui uma forma mais definida e um foco melhor estabelecido do que os proferidos pelo desenvolvimento sustentável quanto às necessárias posturas em relação às políticas econômicas capitalistas.
\end{abstract}

Palavras-chave: Sociologia ambiental; Modernização ecológica; Desenvolvimento sustentável

\begin{abstract}
:
This article has been developed with the mainly objective of investigate what expression has the deepest theoretical contributions for indicate the ways for which the sustainable development can putted in action: the sustainable development itself or the ecological modernization? It was realized a theoretical, qualitative, exploratory and bibliographic research. It has been founded that the ecological modernization acquire a higher analytical point of view, so it has a more defined path and priorities more well established than the ones offered by the sustainable development.
\end{abstract}

Key words: Environmental sociology; Ecological modernization; Sustainable development

\section{Introdução}

Apesar da relevada importância das discussões sobre o meio ambiente e os respectivos impactos provocados pelos seres humanos sobre ele, estes ainda

\footnotetext{
* UEL - Coordenador do Programa de Pós-Graduação em Administração, Doutor em Administração pela FEA/USP. E-mail: munck@uel.br

** UEL - Aluno do Curso de Mestrado em Administração, Especialista em Gestão Empresarial pela FGV. Email: rafaborim@yahoo.com
} 
permanecem como áreas de preocupação. Enquanto não se observa um consenso sobre o fato de que grandes mudanças ambientais, tal como o aquecimento global, estão ocorrendo, verifica-se uma aceitação maior sobre uma realidade impregnada de mudanças em curso, e que, para estas, algumas respostas precisam ser urgentemente concedidas.

Em particular existe uma consideração ambiental amplamente disseminada de que as conseqüências ambientais oriundas da industrialização são incontestavelmente negativas, logo algumas atitudes precisam ser tomadas no intuito de remediar esta realidade calamitosa. Como extensão a esta discussão propõe-se que o desenvolvimento sustentável deveria se tornar tema central na estruturação de políticas ambientais em todas as escalas de poderios governamentais e organizacionais.

Em termos gerais, o conceito de desenvolvimento sustentável requer que as atividades humanas se insiram dentro de determinados limites ecológicos suportados pelo planeta. Para tanto algumas premissas precisam ser consideradas, tais como a equidade inter e intra-gerações, o envolvimento democrático para tomada de decisões relacionadas ao bem estar social e a integração de preocupações econômicas, ambientais e sociais em atos políticos e empresariais. Juntas, estas premissas representam uma modificação considerável para as atividades econômicas das organizações, bem como para a sobrevivência das mesmas. A necessidade de se discutir os problemas ambientais tem, assim, se tornado um lugar comum, ao menos em países mais desenvolvidos.

Algumas divergências começam a surgir quando indagações sobre a coerência do significado da sustentabilidade e sobre os meios de implantação da mesma são postos em perspectiva. Vislumbra-se uma amplitude de opiniões em que cada uma delas confere uma resposta mais apropriada para as mudanças ambientais. Há um espectro de opiniões que se segmentam em duas vertentes opostas: ecologia radical (que exige uma reforma estrutural da sociedade) e a econômica (que acredita na capacidade dos instrumentos mercadológicos de se responsabilizarem por um equilíbrio ambiental em meio às ações advindas das bases socioeconômicas já existentes) (TORGERSON, 1995).

Com o intuito de se investigar uma proposição teórica que viabilize o tratamento da crise ambiental e reformas institucionais incrementais que melhorem o sistema econômico imperante se estabeleceu o presente artigo. Este estudo tem como principal 
intuito colocar em diálogo escolas da sociologia ambiental e selecionar uma que proporcione a viabilidade operacional de um desenvolvimento sustentável. Daí a pergunta de pesquisa: qual expressão possui maior densidade teórica para indicar caminhos para operacionalização das premissas de um desenvolvimento sustentável: o próprio desenvolvimento sustentável ou a modernização ecológica? Após este recorte serão introduzidos o histórico, as abordagens, as proposições e as críticas relacionadas a tal escola sociológica. Em uma das seções do artigo será realizada uma comparação entre o que é proposto pelos adeptos de um estudo somente relacionado ao desenvolvimento sustentável e por pesquisadores que privilegiam a modernização ecológica.

Vale mencionar que o caráter deste artigo, em relação a sua qualificação metodológica, é qualitativo por ser esta uma forma adequada de entender a natureza de um fenômeno social, exploratório por proporcionar maior familiaridade com o problema em investigação e bibliográfico por ser elaborado a partir de contribuições de materiais nacionais e internacionais com devida credibilidade científica (MARTINS; THEÓPHILO, 2007).

\section{Desenvolvimento sustentável e sociologia ambiental}

Hannigan (1995), Klandermans (1992), Spector e Kitsuse (1973) e Taylor (2000) aderem a uma perspectiva construtivista ao observarem o ambiente como uma construção social. Os problemas ambientais são, na verdade, problemas sociais, uma vez que representam constructos sociais reivindicatórios definidos por ações coletivas. Por construção social os autores supramencionados entendem que os problemas ambientais não possuem natureza estática. Eles não podem ser sempre identificados pela realidade identificável, visível e objetiva. Desta maneira, diferentes grupos inseridos em um contexto social identificam e definem os problemas ambientais pelo desenvolvimento e multiplicação de significados e interpretações comunais oriundas das discussões em evidência. Assim, uma perspectiva construtivista está diretamente relacionada à maneira pela qual diferentes pessoas assimilam diferentes conceitos em seu específico mundo social.

Os problemas ambientais são os que primordialmente reivindicam a operacionalização do que se chama por desenvolvimento sustentável. Em face do desafio 
de encontrar um corpo teórico que propicie tal objetivo recorreu-se à sociologia ambiental. De ante mão ressalta-se que não consta nos objetivos deste trabalho a realização de um levantamento bibliográfico extenso sobre a sociologia ambiental. O que se deseja é analisar, brevemente, algumas de suas escolas, e dentre estas extrair aquela que apresente maior coerência com os propósitos do artigo desenvolvido. Assim, não se trata de uma análise finita e esgotável.

A sociologia ambiental, então, é uma escola advinda da sociologia. Para análise da mesma serão consideradas contribuições oriundas das proposições de Catton e Dunlap (apud LENZI, 2006), de Foladori (2001), de Beck (1998) e de Mol (1995, 2000). As contribuições destes autores serão unidas às contribuições de outros autores que discutiram as suas obras.

Catton e Dunlap (apud LENZI, 2006) consideraram que as inúmeras perspectivas teóricas que competiam por um lugar de relevância junto à sociologia contemporânea, tais como o funcionalismo, o interacionismo simbólico, a etnometodologia, a teoria do conflito e o marxismo eram demasiadamente diferentes em suas fundamentações, mas idênticas por uma caracterização antropocêntrica. Por este antropocentrismo foi estruturado o Human Exceptionalism Paradigm (HEP).

Em resposta a este paradigma Catton e Dunlap (apud LENZI, 2006, p.27) "propuseram um novo conjunto de pressupostos que tornariam a sociologia mais sensível à realidade ambiental, que chamaram New Environmental Paradigm (ou NEP)". Em publicação feita no ano de 1978, os autores Catton e Dunlap, como uma conseqüência do NEP, concluíram que "o estudo da interação entre o meio ambiente e sociedade é o núcleo da sociologia ambiental” (LENZI, 2006, p.27).

O Quadro 1 apresenta as principais diferenças entre estes paradigmas. 


\begin{tabular}{|c|c|}
\hline $\begin{array}{c}\text { Pressupostos do Human Exceptionalism Paradigm } \\
\text { - HEP }\end{array}$ & $\begin{array}{l}\text { Pressupostos do New Environmental Paradigm - } \\
\text { NEP }\end{array}$ \\
\hline $\begin{array}{l}\text { 1. Seres humanos são únicos entre as criaturas da } \\
\text { terra devido a sua cultura. }\end{array}$ & $\begin{array}{l}\text { 1. Seres humanos são apenas uma espécie entre } \\
\text { muitas outras interdependentemente envolvidas na } \\
\text { comunidade biótica, que modela a vida. }\end{array}$ \\
\hline $\begin{array}{l}\text { 2. A cultura pode variar indefinidamente e pode } \\
\text { mudar mais rapidamente que os traços biológicos. }\end{array}$ & $\begin{array}{l}\text { 2. Ligações intrincadas de causa e efeito e feedback } \\
\text { na rede da natureza produzem conseqüências não } \\
\text { intencionadas da ação humana intencional. }\end{array}$ \\
\hline $\begin{array}{l}\text { 3. Muitas diferenças são socialmente induzidas } \\
\text { antes do que congênitas, elas podem ser } \\
\text { socialmente alteradas quando vistas como } \\
\text { inconvenientes. }\end{array}$ & \multirow[t]{2}{*}{$\begin{array}{l}\text { 3. O mundo é finito, assim há limites físicos e } \\
\text { biológicos potenciais constrangendo o crescimento } \\
\text { econômico, o progresso social e outros fenômenos } \\
\text { societais. }\end{array}$} \\
\hline $\begin{array}{l}\text { 4. A acumulação cultural significa que o progresso } \\
\text { pode continuar sem limites, tornando todos os } \\
\text { problemas solucionáveis. }\end{array}$ & \\
\hline
\end{tabular}

Quadro 1 - Mudança paradigmática proposta por Catton e Dunlap

Fonte: Catton e Dunlap (apud LENZI, 2006, p.27).

Em 1979 os mesmos autores procuraram conceder uma classificação sobre o que a sociologia discutia com relação às questões ambientais. Desta iniciativa inaugurou-se uma distinção entre a sociologia das questões ambientais e a sociologia ambiental (LENZI, 2006).

A primeira [...] seria ainda tributária de uma sociologia mais tradicional, incorporando apenas marginalmente o tema ambiental, enquanto a última [...] traria a questão ecológica em seu cerne. Além disso, nesse texto ocorre uma reformulação do binômio HEP versus NEP. As siglas passam a ter novos significados: Paradigma do Excepcionalismo Humano (Human Exemptionalism Paradigm - HEP) e Novo Paradigma Ecológico (New Ecological Paradigm - NEP) (LENZI, 2006, p. 27).

Os estudos destes dois pesquisadores têm seqüência com outras publicações, mas em síntese não agregaram grandes inovações. Observa-se pela continuidade de suas proposições algumas situações dúbias, além do retorno ao tão questionado antropocentrismo. Apesar de identificarem como uma das fontes da crise ambiental a identidade cultural dos povos (epistemologia construtivista), eles não conseguem evoluir para um patamar de proposições alternativas para o tratamento desta crise. Eles simplesmente questionam o sistema capitalista e conferem uma responsabilidade heróica às ONGs, ou seja, falham em introduzir um quadro de análise que vislumbre o desenvolvimento de soluções sociais para os problemas ambientais.

Foladori (2001) ao discorrer sobre as bases do conhecimento humano e o meio ambiente, argumenta favoravelmente aos argumentos críticos de Catton e Dunlap (apud 
LENZI, 2006), mas utiliza-se de um discurso marcadamente marxista e enfaticamente caracterizado por um materialismo dialético. Em suas proposições existe um compromisso com uma sociedade coletivista questionadora do modo de operação capitalista. Em alguns momentos, suas considerações a respeito dos sistemas institucionais existentes são tão alarmantes e catastróficas que alcançam um escopo reducionista. Sua ênfase sobre questões unicamente biológicas denunciam uma vertente da sociologia ambiental impossível de se alinhar a discussões que efetivamente possam ser operacionalizadas.

Beck (1998) e Foladori (2001) se assemelham em alguns pontos. Ambos são críticos e acabam por construir uma concepção da realidade respaldada por um corpo de idéias próprias. A posição crítica dos dois autores é extremamente aguçada e as considerações catastróficas se fazem muito presentes em suas narrativas. Beck (1998) introduz a sociologia, no entanto, alguns termos como: teoria da sociedade de risco, modernidade reflexiva e irresponsabilidade organizada.

Goldblatt (1996) ao descrever a contribuição de Beck diz:

\begin{abstract}
A obra de Beck tem uma particular importância para qualquer pessoa interessada na resposta da teoria social à degradação do meio ambiente e à política de ambiente. $\mathrm{O}$ aspecto característico de sua obra consiste em localizar as origens e conseqüências da degradação do ambiente precisamente no centro de uma teoria da sociedade moderna, em vez de considerá-la um elemento periférico ou uma reflexão teórica posterior. A sociologia de Beck e as sociedades que ele descreve são dominadas pela existência de ameaças ecológicas e pela forma como as entendemos e Ihes reagimos. Na realidade, podemos ser levados ao ponto de afirmar que a sociedade de risco é firmada e definida pela emergência destes perigos ecológicos, caracteristicamente novos e problemáticos (GOLDBLATT, 1996, p.228).
\end{abstract}

Quando o autor discorre a respeito da modernidade reflexiva ele deseja expressar um momento em que um paradigma existente, até então fundamentado em conotações incertas, entra em colapso. Neste momento, tudo o que ocorre na sociedade, objetiva e subjetivamente, passa a ser foco de análise, situação que denuncia o elevado nível de incerteza que impregna as relações sociais. Como impacto desta incerteza verifica-se que agentes sociais rompem de forma drástica com suas crenças ao se desvencilharem de qualquer comprometimento institucional (COHEN, 1997). 
A teoria da sociedade de risco, em parte justificada por uma modernidade reflexiva, é complementada pela noção de uma irresponsabilidade organizada, por meio da qual nota-se "um encadeamento de mecanismos culturais e institucionais pelos quais as elites políticas e econômicas encobrem efetivamente as origens e conseqüências dos riscos e dos perigos catastróficos da recente industrialização" (GOLDBLATT, 2006, p.241).

Apesar de introduzir uma nova teoria, a da sociedade de risco imersa em conotações construtivistas, Beck (1998) vai além das críticas realizadas por Foladori (2001). Este ainda assume uma abordagem marxista, enquanto aquele critica o sistema capitalista, ou seja, nega qualquer possibilidade de análise funcionalista, e também rompe com as premissas aliadas ao marxismo. Trata-se, portanto, de uma abordagem inovadora da sociologia ambiental, mas que também não permite a análise do desenvolvimento sustentável em termos operacionais.

O que pode ser observado em comum entre Catton e Dunlap (apud LENZI, 2006), Foladori (2001) e Beck (1998) é uma adesão aos princípios revolucionários dos movimentos ambientalistas. Dentre eles, destaca-se o movimento da justiça ambiental, para muitos definidos não mais como um simples movimento, mas como um paradigma de interpretação e ação para as causas ambientais mundiais (TAYLOR, 2000). Estes grupos são essencialmente radicais e bem por isso apresentam uma atividade crítica muito aguçada. Entretanto, todos eles, assim como as abordagens da sociologia ambiental defendidas pelos autores anteriormente mencionados, não propõem mudanças e metodologias de resposta, uma vez que ficam demasiadamente presos ao enfoque crítico da situação contemporânea.

Não se questiona a validade de suas assertivas, ao contrário todas são consideradas em relação às discussões que propõem, todavia elas são utilizadas apenas como fonte de novos estudos interessados em promover melhorias em diferentes ambientes sociais, como por exemplo, as organizações. As premissas que sustentam estes movimentos e estas vertentes da sociologia ambiental são: a extinção do sistema capitalista, a reivindicação por práticas econômicas não baseadas em processos de produção, melhores condições de vida para todas as camadas sociais e a atuação sobre problemáticas ambientais por meio de vias radicalistas e revolucionárias (BUTTEL, 2000; MOL, 2000; TAYLOR, 2000). 
Esta caracterização apenas comprova as considerações anteriores sobre a impossibilidade de utilizar tais vertentes da sociologia ambiental em um estudo que se interesse por operacionalizar as premissas do desenvolvimento sustentável. Mol (2000) traz uma resposta a esta necessidade. Em seu artigo The environment movement in an era of ecological modernization, publicado em 2000, ele realiza uma brilhante explicação do processo de enfraquecimento, transformação e adaptação destes movimentos ambientais. Estes passam a aceitar o sistema capitalista por uma visão dúbia: por ele se originam os problemas causadores de uma crise ambiental, mas é por ele que se originam as soluções.

Mol (2000) traz a tona uma nova escola da sociologia ambiental, denominada de teoria da modernização ecológica, a qual aceita o problema ambiental por uma via construtivista e o trata por considerações funcionalistas. O exercício da crítica não está excluído nas fundamentações da teoria da modernização ecológica, ao contrário, é por este que a teoria tem se aprimorado constantemente. A ênfase desta proposição teórica está em economizar a ecologia e ecologizar a economia, por meio de uma série de transformações institucionais, as quais permitirão o funcionamento do sistema capitalista por métodos de atuação mercadológicas mais responsáveis (GIBBS, 2000; JÄNICKE, 2007).

\section{A teoria da modernização ecológica}

Entende-se por modernização ecológica uma perspectiva de conhecimentos enraizada na sociologia ambiental, uma das disciplinas estudadas pelas ciências sociais. A modernização ecológica tem adquirido influência junto à sociologia ambiental e também, mas em menor escala de relevância, junto às ciências geográficas e políticas. Pela amplitude de abordagens da literatura internacional sobre modernização ecológica, esta tem sido continuamente pesquisada por sociólogos e neste artigo em específico, adota-se a abordagem explorada pela sociologia ambiental.

Para Buttel (2000) a ascensão da modernização ecológica como uma perspectiva teórica da ciência da sociologia ambiental é admitida como meteórica e inesperada por inúmeros autores. Esta denominação tem surgido para apresentar uma possível teoria a ser reconhecida como uma representante de discussões atuais sobre sustentabilidade, a qual deve permanecer e dialogar com corpos de conhecimentos antigos e de relevante 
influência junto a sociologia ambiental em temas referentes às tradições de produção do sistema capitalista (muito exploradas por Schnaiberg, 1980), às noções sobre o paradigma do excepcionalismo humano e ao novo paradigma ambiental (pesquisados por Catton e Dunlap apud LENZI, 2006).

Nos anos de 1980 um grande número de sociólogos e outros cientistas sociais que tinham a deterioração ambiental e a reforma ambiental como temas centrais aos seus estudos começaram a observar que algumas mudanças significantes começavam a tomar lugar junto ao discurso ambiental, às políticas ambientais e às instituições até então responsáveis por tratar as problemáticas ambientais. Começavam a ser estabelecidos debates não muito radicais, os quais se preocupavam em responder a estas transformações ocorrentes por uma nova linguagem e uma nova abordagem estrutural, ambas inseridas em um contexto de discussão alicerçado por preocupações com o meio ambiente, daí o surgimento da teoria da modernização ecológica (MOL, 2000).

Jänicke (2007) complementa que o termo modernização ecológica foi introduzido com o intuito de fornecer uma fórmula que integrasse ecologia e economia. A intenção era unir, à orientação dos processos de modernização, os mercados econômicos em desenvolvimento às práticas de desenvolvimento ambiental até então caracterizadas como amenas. Por esta união entre ecologia e economia, York e Rosa (2003) não hesitam em admitir que a teoria da modernização ecológica tem se desenvolvido como uma teoria neoliberal e, também, como uma das teorias mais relevantes da sociologia ambiental.

A mesma modernização ecológica é aceita por Gibbs (2000) como uma abordagem que observa, investiga e propõe alternativas para a problemática ambiental. Para o autor, a modernização ecológica argumenta que o desenvolvimento econômico e a crise ecológica (ou ambiental) podem coexistir e, por conseguinte, induzir a formação de um novo modelo de desenvolvimento à economia capitalista. Como uma abordagem de pesquisa, a modernização ecológica é especificamente adotada para conciliar orientações teóricas e empíricas em respostas coerentes para os problemas ambientais.

Em termos gerais, o objetivo da teoria da modernização ecológica está em analisar como as sociedades industriais contemporâneas se comportam em relação à crise do meio ambiente (MOL; SPAARGAREN, 2000). Esta teoria propõe que o contínuo desenvolvimento industrial, ao invés de degradar o meio ambiente, oferece a melhor 
alternativa para se escapar de uma ruptura ecológica global. Para York e Rosa (2003) uma idéia central à teoria da modernização ecológica está em que os níveis elevados de industrialização, de desenvolvimento tecnológico e de crescimento econômico são não somente compatíveis com a sustentabilidade ecológica, mas também orientadores de uma reforma ambiental maior.

Uma vez introduzida a teoria da modernização ecológica passa-se a seguir para uma discussão que abordará o histórico e a estruturação deste corpo teórico.

\section{A teoria da modernização ecológica: histórico, abordagens e estrutura}

O conceito de modernização ecológica foi primeiramente aplicado por um grupo de pesquisa gerido pelo Berlim Business Center e adotado por uma pequena comunidade de cientistas sociais alemães, algumas vezes caracterizados como a escola alemã de política ambiental (JÄNICKE, 2007).

Mol (2000) e Buttel (2000) comungam sobre uma história literária da modernização ecológica segmentada em duas diferentes gerações. A primeira geração é composta por estudos realizados em toda a década de 1980 e início da década de 1990, os quais foram conduzidos principalmente por pesquisadores alemães e holandeses. Esta primeira geração se baseou nos pressupostos gerais de que uma democracia liberal capitalista possui a capacidade institucional de processar e amenizar seus impactos sobre o ambiente natural e também na premissa de que o desenvolvimento pleno de uma democracia liberal e capitalista resultaria na melhoria dos resultados ecológicos. Já a segunda geração, introduzida em meios da década de 1990, avessa a primeira, gira em torno de estudos que procuram identificar processos sociopolíticos específicos por meio dos quais a modernização das democracias liberais e capitalistas incentiva ou bloqueia resultados ecológicos mais benéficos.

Ao longo destas duas gerações Buttel (2000) identifica quatro abordagens diferentes sobre as quais a modernização ecológica é empregada: a escola sociológica da modernização ecológica; a modernização ecológica como padrão descritivo para os discursos ambientais; a modernização ecológica como sinônima para estratégias de gestão ambiental; e a modernização ecológica como noção de política de inovação 
ambiental ou progresso ambiental. Estas abordagens são exploradas e detalhadas no Quadro 2.

Estas quatro abordagens constroem a teoria da modernização ecológica. É possível perceber que estas abordagens ocorrem simultaneamente. No entanto, a força representativa de cada uma delas se altera com o decorrer do tempo. O início das discussões sobre a teoria da modernização ecológica se deu por um enfoque mais nacional e elitista, enquanto que o desenvolvimento de seu discurso começou a observar menores escalas de análise (países em desenvolvimento, grupos sociais, organizações) por processos de avaliação de métodos sociais mais participativos (SONNENFELD; MOL, 2002).

$\mathrm{Na}$ literatura sobre modernização ecológica observa-se um interesse de comparar estas gerações e abordagens por metodologias que incluam em suas análises situações que tratem dos meios pelos quais o processo de globalização pode, e deve, catalisar as ações de modernização ecológica evidenciada em nações desenvolvidas ou em desenvolvimento.

\begin{tabular}{|c|c|c|}
\hline Abordagem & Descrição & Autores \\
\hline Primeira & $\begin{array}{l}\text { Existe uma escola sociológica da modernização ecológica. Esta é oriunda } \\
\text { de uma perspectiva norte americana e britânica, discutida principalmente } \\
\text { por Arthur P.J. Mol e Gert Spaargaren (2000), dois autores admitidos } \\
\text { como figuras centrais ao debate em questão. No entanto, na Alemanha e } \\
\text { na Holanda e em demais países europeus que tratam sobre a } \\
\text { modernização ecológica existe uma valorização das proposições } \\
\text { realizadas pelos pesquisadores Joseph Huber (2000) e Martin Jänicke } \\
\text { (2007). }\end{array}$ & $\begin{array}{l}\text { HUBER } \\
(2000) \\
\text { JÄNICKE } \\
(2007) \\
\text { MOL \& } \\
\text { SPAARGAREN } \\
(2000)\end{array}$ \\
\hline Segunda & $\begin{array}{l}\text { Representa-se por uma noção de descrição predominante dos discursos e } \\
\text { políticas ambientais. A maior personagem acadêmica associada a esta } \\
\text { perspectiva político-discursiva e social-construtivista é o autor Hajer. Para } \\
\text { ele a modernização ecológica não se trata de uma predição de tendências } \\
\text { fortes em relação as indústrias envolvidas em progressos ecológicos, mas } \\
\text { sim de uma categoria de descrição dos discursos de políticas ambientais } \\
\text { promovidos em países desenvolvidos. O construtivismo de Hajer (1995) } \\
\text { está no extremo oposto do objetivismo explícito na literatura da } \\
\text { modernização ecológica, bem por isso, ele considera que o tema deve } \\
\text { servir como um diluente aos impulsos políticos direcionados as reformas } \\
\text { ambientais, pela compreensão de que limites responsáveis de expansão } \\
\text { econômica, crescimento do consumo e a intensiva capacidade de } \\
\text { mudança tecnológica comprometem a habilidade dos estados validarem } \\
\text { uma maior qualidade de políticas ambientais. Para muitos estudiosos } \\
\text { (inclusive para os adeptos da visão tradicional da modernização } \\
\text { ecológica) o caráter social e construtivista dos trabalhos de Hajer é } \\
\text { hostilizado por ser considerado como incompatível as premissas da } \\
\text { modernização ecológica. }\end{array}$ & $\begin{array}{l}\text { HAJER } \\
(1995)\end{array}$ \\
\hline Terceira & $\begin{array}{l}\text { Quando a modernização ecológica é freqüentemente utilizada como um } \\
\text { sinônimo para estratégias de gestão ambiental, ecologia industrial, eco- } \\
\text { reestruturação etc (HAWKEN, 1993; AYRES, 1998). De fato, a literatura }\end{array}$ & $\begin{array}{l}\text { ANDERSEN } \\
(1994) \\
\text { AYRES }\end{array}$ \\
\hline
\end{tabular}




\begin{tabular}{|c|c|c|}
\hline & $\begin{array}{l}\text { predominante sobre modernização ecológica possui uma tendência de } \\
\text { conceder uma ênfase primária aos progressos ambientais conquistados } \\
\text { pelo setor privado, particularmente em relação as indústrias de } \\
\text { manufatura e setores associados a estas atividades. Os cientistas sociais, } \\
\text { no uso de várias abordagens teóricas (SCHNAIBERG, 1980; ANDERSEN, } \\
\text { 1994), utilizam esta mesma noção de modernização ecológica para } \\
\text { referirem-se aos comportamentos dos setores privados e pesquisarem os } \\
\text { fatores que possibilitam o aumento de eficiência e a redução de poluição } \\
\text { e dispêndio de recursos naturais. }\end{array}$ & $\begin{array}{c}(1998) \\
\text { HAWKEN } \\
(1993) \\
\text { SCHNAIBERG } \\
(1980)\end{array}$ \\
\hline Quarta & $\begin{array}{l}\text { Existem alguns autores que utilizam uma noção de modernização } \\
\text { ecológica para referirem-se a qualquer política de inovação ambiental ou } \\
\text { progresso ambiental. Murphy (1997), por exemplo, se refere as políticas } \\
\text { estadistas que fazem possíveis as internalizações das externalidades } \\
\text { ambientais, as quais ele considera como instâncias da modernização } \\
\text { ecológica. }\end{array}$ & $\begin{array}{c}\text { MURPHY } \\
\text { (1997) }\end{array}$ \\
\hline
\end{tabular}

Quadro 2 - As abordagens da teoria da modernização ecológica

Fonte: elaborado pelo autor a partir das considerações de ANDERSEN (1994); AYRES (1993); BUTTEL (2000); HAJER (1995); HAWKEN (1993); HUBER (2000); JÄNICKE (2007); SCHNAIBERG (1980); MOL, SPAARGAREN (2000); MURPHY (1997).

Hajer (1993) está entre estas tendências, principalmente naquela relacionada à segunda geração da modernização ecológica. Para ele a teoria da modernização ecológica alcança duas interpretações: a primeira é uma interpretação tecno-corporativista que prioriza a economização da natureza e estruturas de decisões elitistas e, a segunda, que é uma interpretação mais próxima das visões de sustentabilidade, a qual não somente enfatiza mudanças para a produção e para o consumo, mas prioriza estas transformações por uma veia mais democrática, distributiva e amparada pelas proposições da justiça social (HAJER, 1993). Christoff, citado por Gibbs (2000), visualiza estas duas interpretações como espectros fortes e fracos da modernização ecológica, os quais são explanados por meio do Quadro 3.

\begin{tabular}{|l|l|}
\hline \multicolumn{1}{|c|}{ Modernização ecológica fraca } & \multicolumn{1}{|c|}{ Modernização ecológica forte } \\
\hline $\begin{array}{l}\text { Soluções tecnológicas para os problemas } \\
\text { ambientais }\end{array}$ & $\begin{array}{l}\text { Amplas mudanças nas estruturas institucionais e } \\
\text { econômicas da sociedade por meio da } \\
\text { incorporação de preocupações ecológicas }\end{array}$ \\
\hline $\begin{array}{l}\text { Estilos tecnocráticos e corporativistas de } \\
\text { elaboração de políticas realizados pelas elites } \\
\text { cientificas, econômicas políticas }\end{array}$ & $\begin{array}{l}\text { Tomada de decisões por processos abertos e } \\
\text { democráticos, marcados pela participação e } \\
\text { envolvimento da sociedade }\end{array}$ \\
\hline $\begin{array}{l}\text { Restrito a nações desenvolvidas que se utilizam da } \\
\text { modernização ecológica para consolidar suas } \\
\text { vantagens econômicas globais }\end{array}$ & $\begin{array}{l}\text { Preocupada com as dimensões internacionais do } \\
\text { meio ambiente e desenvolvimento econômico }\end{array}$ \\
\hline $\begin{array}{l}\text { Impõe uma estrutura fechada, rígida e unilateral } \\
\text { de desenvolvimento político e econômico }\end{array}$ & $\begin{array}{l}\text { Uma abordagem mais aberta não participada de } \\
\text { uma visão unilateral, mas por múltiplas } \\
\text { possibilidades orientadas por premissas da } \\
\text { modernização ecológica. }\end{array}$ \\
\hline
\end{tabular}

Quadro 3 - Modernização ecológica fraca e forte

Fonte: Christoff apud GIBBS (2000). 
Hajer (1995) desenvolve esta idéia de modernização ecológica forte como uma modernização ecológica reflexiva, por meio da qual o desenvolvimento político e econômico avançam sobre bases críticas de auto-conhecimento social, ao envolver em seu discurso questões como o escrutínio público e controle democrático, enquanto que a modernização ecológica fraca envolve uma linha de debates sobre economias capitalistas já ameaçadas pela crise ecológica.

Uma vez compreendido o histórico, a estrutura e as abordagens desta teoria, acredita-se ser possível caminhar com a discussão ao apresentar as relações e os propósitos da teoria da modernização ecológica, o que é feito no próximo tópico, para em seguida o conceito de desenvolvimento sustentável ser abordado.

\section{Teoria da modernização ecológica: proposições}

Ainda que consideradas algumas diferenças enfáticas como as demonstradas no tópico anterior, a teoria da modernização ecológica, de acordo com Mol (2000), encontra alguns denominadores comuns nos seguintes fatores: a deterioração ambiental é compreendida como um desafio que para ser superado requer uma forma econômica amparada por uma força sócio-técnica, logo, a crise ambiental não é aceita como uma conseqüência inevitável advinda de estruturas institucionais existentes; uma ênfase maior é concedida para instituições modernas responsáveis por promover reformas ambientais, tais como as relacionadas aos assuntos específicos e tecnológicos, logo, as nações, as políticas globais e o mercado global são vislumbrados nos processos de modernização ecológica; e, em termos acadêmicos adota-se uma posição menos rigorosa do que a praticada pelos neo-marxistas e outras contribuições advindas de grupos pós-modernos que pregam o fim do sistema de produção capitalista.

Mol e Spaargaren (1993) endossam estes denominadores comuns por admitirem que o comprometimento da modernização ecológica com o projeto da modernidade e o seu potencial em desenvolver um capitalismo sustentável provém da crença de que todas as alternativas apresentadas para a presente ordem econômica têm se mostrado inaplicáveis mediante uma série de critérios econômicos, ambientais e sociais.

Buttel (2000) informa que as proposições da modernização ecológica hipotetizam que, enquanto os problemas ambientais mais desafiadores deste século (e do seguinte) 
têm sido causados por processos de modernização e industrialização, suas respectivas soluções estão em discussões que vão muito além do que simples considerações sobre redução dos níveis de modernização e industrialização. Em palavras diferentes, levanta-se a hipótese de que não somente o capitalismo é institucionalmente flexível para promover uma nova direção sustentável do sistema, mas a sua intrínseca competição entre capitais, pode, sobre determinadas condições políticas, realizar a constituição de uma nova estrutura orientada para a promoção de processos produtivos menos poluidores e mais eco-eficientes, além de práticas de consumos mais conscientes (MOL; SPAARGAREN, 1993).

Assim, como uma teoria social, a modernização ecológica deve reconhecer e teorizar sobre como a função da eco-eficiência capitalista e a racionalização de recursos podem influenciar as reformas ambientais. Considera-se a modernização ecológica uma resposta crítica, senão decisiva, ao ambientalismo radical. A modernização ecológica compreende o ambiente como um espaço autônomo e ilimitado para tomada de decisões (a emancipação da ecologia). Por último, mas talvez a hipótese mais fundamental, está em acreditar que os processos de modernização ecológica representam uma reflexão das políticas ambientais, tornadas possíveis por uma reestruturação estatal (BUTTEL, 2000; MOL, 1995).

Ao invés de uma posição ecológica radical e restruturante a modernização ecológica, então, afilia-se a versões de sustentabilidade que consideram um processo de modernização progressiva das instituições da sociedade moderna, ou seja, o oposto da destruição e desaparecimento das mesmas (MOL; SPAARGAREN, 1993). A modernização ecológica propõe que uma transformação estrutural precisa ocorrer em um nível macroeconômico, por meio da utilização, em diferentes firmas, de tecnologias novas e limpas (GOULDSON; MURPHY, 1997).

Gibbs (2000) consente a respeito desta escala macro, mas defende que a modernização ecológica também deve ser implementada para informar, teoricamente, uma relação com as escalas sub-nacionais. Neste modelo, as soluções para os problemas ambientais são desenvolvidas dentro de determinadas condições estruturais e dentro de determinados contextos situacionais, ao envolver atores e estratégias, juntamente com os fatores institucionais, econômicos e informativos. 
Em um quadro como este, Jänicke (2007) admite que a consideração das possíveis vantagens econômicas e respectivos benefícios da modernização ecológica é essencial ao debate estabelecido. A mesma importância deve ser concedida a discussões sobre a capacidade governamental de manter, simultaneamente, uma economia que respeite o meio ambiente e que cresça progressivamente em termos tecnológicos e financeiros.

Esta admoestação remete as assertivas de Sonnenfeld e Mol (2002), para os quais a modernização ecológica tem se concentrado em uma reforma ambiental localizada em níveis representados pelos governos, pelos movimentos ambientais, pelas empresas e, também, por diferentes formas de organizações sociais.

Gibbs (2000) complementa a discussão ao mencionar que o conceito de modernização ecológica pode ser utilizado em dois níveis principais. O primeiro relacionase a um conceito teórico que analisa as mudanças necessárias de serem vivenciadas por instituições centrais da sociedade moderna, as quais promoverão respostas para questões da crise ecológica. O segundo remete à utilização da modernização ecológica como padrão de descrição para um programa político, ou seja, trata-se de um nível mais pragmático utilizado para redirecionar os feitos em políticas ambientais. Em relação ao primeiro significado a modernização ecológica clama por uma mudança maior ou uma transformação ecológica nos processos de industrialização, os quais levam em conta a necessidade de se manter uma base sustentável. Quanto ao segundo significado, o de um programa político pragmático, a modernização ecológica deve ser auxiliada por diferentes organizações, uma vez que envolve vantagens financeiras e responde a questões ambientais por noções de lucros empresariais.

A modernização ecológica enquanto teoria social assume a responsabilidade de promover o acontecimento do desenvolvimento sustentável em um sistema capitalista e para tanto necessita do aporte de esferas governamentais, sociais, ambientais e organizacionais (SONNENFELD; MOL, 2002). A estruturação destas proposições se dá por uma série de premissas, as quais advêm de inúmeros autores adeptos a esta teoria. De todas as considerações proferidas por estes pesquisadores, foram selecionadas aquelas que melhor exemplificam e ilustram as proposições da teoria da modernização ecológica. Apresentam-se abaixo estes sustentáculos da teoria:

As forças orientadoras de uma modernização ecológica são (JÄNICKE, 2007): 
- A lógica capitalista e a competitividade por inovações em combinação com a potencialidade do mercado em relação às necessidades ambientais globais: soluções tecnológicas para problemas ambientais oferecem relações de negociações nas quais todos os participantes ganham;

- As regulamentações ambientais coerentes quando inicialmente implantadas por alguns países nos quais as pressões ambientais e a grande capacidade de inovação se tornaram aliadas para motivar o desenvolvimento de vantagens competitivas. As regulamentações ambientais são pré-requisitos para os processos de inovação e difusão; e,

- A insegurança sobre o crescimento econômico e os riscos para as indústrias poluidoras no contexto de aumento da complexidade da governança ambiental global. Este aumento nos riscos de negócios faz da modernização ecológica um porto seguro para empresas intensivamente ambientais.

Como um programa político pragmático, a modernização ecológica concede respostas às questões ambientais por noções de lucros empresariais em cinco diferentes maneiras (DRYZEK, 1997):

- A redução da poluição e do consumo de poluentes resulta em maior eficiência do negócio;

- A abolição de dívidas futuras, tais como as obrigações de tratar os ambientes contaminados pelas atividades empresariais;

- Por meio da venda de produtos ambientalmente amigáveis;

- Por meio da comercialização de tecnologias que previnem e extinguem a poluição; e,

- A criação de um ambiente melhor angaria benefícios na atração de uma força de trabalho melhor qualificada.

A modernização ecológica provê condições para ações ambientais efetivas por meio da ascensão de uma estrutura amparada por diversos atores sociais, constituída por (GIBBS, 2000):

- Um sistema cognitivo e informativo. As condições estruturais, dentro de um determinado conhecimento ambiental, são produzidas, distribuídas, interpretadas e aplicadas; 
- Um sistema político institucional que engloba as estruturas institucionais, legais, regras e normas institucionalizadas de uma sociedade; e,

- Um sistema tecnológico e econômico que inclui desempenho econômico, níveis tecnológicos e composições setoriais.

O contexto da modernização ecológica, então, admite uma valorização do padrão econômico capitalista, reconhece a importância da atuação regulamentadora do estado em questões ambientais, admite a necessidade de movimentos ambientais para fiscalizarem tanto o governo quanto as empresas, e estas são reconhecidas como fundamentais para os processos envoltos a modernização ecológica, uma vez que são responsáveis pelo giro econômico, abastecimento de necessidades sociais básicas por meio de suas atividades produtivas e prestações de serviços, e relacionamento intensivo com o meio ambiente.

Pelas empresas surgem processos alinhados com as determinações governamentais e por elas se estabelecem ações de resposta às cobranças proferidas pelos movimentos ambientais. É por meio delas, também, que a economia se desenvolve, que empregos são gerados e que resultados sociais benéficos podem ser alcançados. Suas atividades fins possibilitam o pagamento de impostos, a remuneração de seus funcionários, a distribuição de lucros entre os acionistas, mas também devem preocupar-se com a sustentabilidade de suas operações e negociações em termos ambientais, sociais e econômicos.

\section{Desenvolvimento sustentável ou modernização ecológica?}

O desenvolvimento sustentável é concebido por muitos autores como um tema inserido nas proposições da modernização ecológica. Eles compreendem a teoria da modernização ecológica como um conjunto macro dentro do qual se vislumbra as exigências por um desenvolvimento sustentável.

Embora a utilização do termo 'desenvolvimento sustentável' tenha sido usada em tempos anteriores, ele foi popularizado na publicação do Relatório Brundtland (1987). A definição utilizada por Brundtland (1987) enfatiza o suprimento das necessidades do presente sem comprometer a habilidade de gerações futuras sanarem suas condições de 
sobrevivência. Apesar das definições sobre desenvolvimento sustentável variarem, muitas delas fazem alusão aos seguintes princípios fundamentais (GIBBS, 2000):

- Qualidade de vida (incluindo e unindo aspectos sociais, econômicos e ambientais);

- Cuidados com o meio ambiente;

- Preocupações com o futuro e princípios de precaução;

- Noções de justiça e equidade; e,

- Relações participativas e promotoras de parcerias sociais.

Trata-se de um tema muito discutido, contestado e até mesmo massificado. Torgerson (1995) comenta sobre a ambigüidade do termo e também considera a maneira sobre a qual é permitida aos atores políticos em procederem sem um acordo específico sobre as ações a serem tomadas em direção a reformas incrementais ao invés das reformas radicais tão defendidas pelos ecologistas radicais. Dryzek (1997) complementa esta miscelânea de contribuições ao admitir o desenvolvimento sustentável como um simples discurso ambientalista como muitos outros, mas que, dentre eles, exerce certa dominância.

O desenvolvimento sustentável pode ser entendido como um discurso que prioriza um alcance de poder além daquele participado pelas nações. Para Luke (1995) os discursos do desenvolvimento sustentável podem ser relidos por uma nova formação que integra poder e conhecimento, que tem por objetivo a acumulação de poder para comunidades sub-nacionais e supranacionais menos representativas, por meio da mobilização de novos conhecimentos sobre o desempenho econômico de diferentes nações que realizam o seu crescimento por métodos de governo irresponsáveis. Ao invés de focar os territórios e nações soberanas, estes discursos procuram, em domínios subnacionais e transnacionais, por ecossistemas sustentáveis para reconfigurar os circuitos de geração e utilização de poderes ecológicos.

Sonnenfeld e Mol (2002) comentam que apesar de haverem tendências que rumem nestas duas direções (sub-nacionais e supranacionais), percebe-se que a noção de estadonação ainda permanece como prioridade das atividades regulatórias ao redor do planeta. Nesta escala, apesar de uma ampla aceitação do conceito de desenvolvimento sustentável como base para elaboração das políticas ambientais, observa-se uma 
tendência maior, dentre as nações industrializadas, de se priorizar um discurso que ampare estas mudanças por uma economia voltada para as vontades do mercado, ou seja, para um cenário de globalização econômica alicerçado em um sistema de acordos livres, o qual se contrapõe a aceitação de um desenvolvimento sustentável efetivo.

Se compreendido que o sistema econômico capitalista baseado em mercados procura por um padrão de dominação global e econômico, uma resposta tem sido o argumento de que a integração entre políticas econômicas e ambientais pode ser simultaneamente lucrativa para as organizações e contributiva para o alcance de um desenvolvimento sustentável por meio de processos de modernização ecológica (GIBBS, 2000).

Hajer (1995) e Harvey (1996) conectam a modernização ecológica ao desenvolvimento sustentável por um discurso central e político baseado na teoria da modernização ecológica. No entanto, a teoria da modernização ecológica possui um rigor analítico superior ao participado pelo desenvolvimento sustentável e participa de uma forma mais definida e um foco melhor estabelecido do que os proferidos pelo desenvolvimento sustentável quanto às necessárias posturas em relação às políticas econômicas capitalistas. (DRYZEK, 1997).

Buttel (2000) concorda com Dryzek (1997) ao afirmar que o conceito de desenvolvimento sustentável não poderia se estabelecer como uma contribuição que superaria uma série de interrogações por meio de um corpo de conhecimento nebuloso e, ainda mais, impreciso para construir um conjunto coerente de hipóteses que confluiria na geração de inúmeros grupos de pesquisa. Talvez, pelo reconhecimento deste fato, alguns dos pensadores mais inovadores vinculados as premissas da teoria da modernização ecológica, particularmente Mol e Spaargaren (1993), direcionaram esforços consideráveis no intuito de alavancar a modernização ecológica como um fenômeno já existente e implícito à teoria social.

Buttel (2000) e Weidner (2002) confirmam as considerações de Mol e Spaargaren (1993) e ressaltam que a modernização ecológica requer um comprometimento político com preocupações de longo prazo, o que ocorre por uma abordagem mais holística direcionada ao desenvolvimento econômico e a crise ambiental. O trabalho de Jänicke (2007) sugere que a habilidade das nações em empreender estas abordagens holísticas 
resultam de uma interação entre seus desempenhos econômicos e as suas capacidades para inovação, pensamento estratégico e práticas de governos consensuais, muitas das quais, de acordo com o autor, dependentes das organizações contemporâneas.

A teoria da modernização ecológica avança sobre as proposições de um desenvolvimento sustentável por inúmeras diferenças, tais como a apresentada por Gibbs (2000) que diz que enquanto o desenvolvimento sustentável considera que o poder deve ser distribuído simultaneamente em escalas internacionais e locais, a modernização ecológica não necessariamente exige o desagrupamento da noção de estado-nação.

Todavia, enquanto alguns autores reconhecem que a localização do espaço de discussão pode ser algo desejável, a intensificação da internacionalização das relações sociais e o aumento da distância temporal e espacial dentro das sociedades modernas faz com que a realização das metas da modernização ecológica se realizem em um contexto de experimentos locais, os quais não estão isentos das relações de poderes e forças de mercado muito debatidas somente em níveis de discussões internacionais (SPAARGAREN; MOL, 1992).

Apesar de uma teoria neoliberal, Mol e Spaargaren (1993) criticam uma visão de desenvolvimento demasiadamente técnica e desvinculada de regulamentações, uma vez que é muito difícil a realização de uma modernização ecológica sem a intervenção estatal em vários níveis. Os experimentos locais supramencionados são realizados em grande parte pelas organizações, as quais, para aderirem ao contexto de uma modernização ecológica, precisam obedecer algumas normatizações e exigências oriundas de órgãos e atores com poderes de regulamentação devidamente legitimados (JÄNICKE, 2007).

Assume-se, então que o desenvolvimento sustentável é um conceito antecessor da teoria da modernização ecológica, audacioso e abrangente, uma vez que engloba questões sociais, econômicas e ambientais em suas proposições, todavia truncado por não apresentar métodos que viabilizem soluções para os problemas ambientais, o que permite inferir sobre a superioridade da teoria da modernização ecológica nessa perspectiva. Esta, como todas as teorias possuem falhas, críticas e limitações, as quais são exploradas em seqüência. 


\section{Críticas à teoria da modernização ecológica}

Este estudo inova ao agregar as contribuições da teoria da modernização ecológica em um contexto de pesquisa brasileiro. Mas, uma vez que se observa uma movimentação de comunidades sociais e científicas rumo a uma exploração das proposições e abordagens apresentadas por este corpo teórico, é necessário fazê-lo por trabalhos que reconheçam suas forças e fraquezas.

Primeiramente, de acordo com a vernácula de Buttel (2000), evidencia-se que os pensamentos envoltos às proposições da modernização ecológica não foram desenvolvidos por pontos de vistas comuns e identificáveis a um determinado conjunto de postulados, logo, não é possível notar muitos acordos quanto às suas principais hipóteses de pesquisa. A modernização ecológica tem sido fortemente orientada por preocupações e transformações extra-teóricas, bem como tem sido utilizada, basicamente, como um conceito misto entre a ciência ambiental e a política ambiental, o qual emerge por meio de contribuições oriundas de diversas ordens de leituras teóricas.

Em relação à prática da modernização ecológica, Jänicke (2007) destaca alguns limites:

- O crescimento econômico tende a neutralizar as melhorias ambientais se o crescimento da eco-eficiência permanecer no caráter incremental, se as inovações ambientais continuarem restritas a determinados nichos ecológicos, e, se as soluções providas tratarem apenas de sintomas e não das causas efetivas dos problemas ambientais.

- A modernização ecológica reconhece a resistência de prejudicadores da modernização, geralmente dotados de poderes que permitem a limitação do escopo e efeitos de uma política ambiental efetiva. Estes agentes podem não ser fortes o suficiente para prevenir inovações ambientais políticas baseadas em conhecimento, mas, quando se fala de implementação das políticas já existentes, a resistência do poder de base permanece como um importante obstáculo.

Harvey (1996) complementa estas limitações com certas noções de risco implícitas à teoria da modernização ecológica. Segundo ele, enquanto esta discussão apresenta a modernização ecológica como uma possibilidade plausível de transformação das 
economias capitalistas, ela ainda pode ser utilizada como um discurso mentiroso e corrupto dotado de um único interesse, o de dominar os meios de poder econômico. Por esta abordagem, segundo Gibbs (2000), pode-se alcançar uma dominação global de recursos naturais por industrias transnacionais, governos nacionais e grandes movimentos científicos em nome da sustentabilidade.

Por fim, admoesta-se que os autores que atualmente militam em favor da modernização ecológica, ou aqueles que futuramente participarão deste movimento, devem reconhecer que esta perspectiva, como afirmam York e Rosa (2003), possui algumas deficiências sedentas de uma correção imparcial. Estas incluem a visão eurocêntrica predominante (o fato das raízes teóricas e empíricas desta teoria terem sido extraídas de países do norte europeu, cujos padrões de vida são muito distintos daqueles vivenciados por grande parte das nações do planeta), a excessiva ênfase sobre indústrias transformativas, a preocupação predominante com fatores de eficiência e controles de poluição ao invés de questões mais importantes como o consumo de recursos naturais e seus respectivos impactos ambientais, a abordagem não crítica sobre as potencialidades inovadoras do capitalismo moderno, e o fato de inúmeras questões fundamentais ainda não respondidas sobre os fenômenos da modernização ecológica não serem contemplados na estruturação da teoria da modernização ecológica.

\section{Considerações Finais}

Foi observado que a sociologia ambiental, uma das escolas ramificadas da sociologia, possui uma diversidade de abordagens, das quais algumas foram brevemente comentadas. Destas concluiu-se que a teoria da modernização ecológica representou apresenta contribuições teóricas mais relevantes para um objetivo de se operacionalizar o desenvolvimento sustentável

Esta teoria é comumente utilizada em quatro abordagens: como uma escola sociológica da modernização ecológica; como um padrão descritivo para os discursos ambientais; como um sinônimo para estratégias de gestão ambiental; e, como noção de política de inovação ou progresso ambiental.

Verificou-se, também, a presença de duas gerações literárias em referência a esta teoria. A primeira, localizada entre os inícios dos anos 1980 e 1990, considera que os 
impactos ambientais são simultaneamente gerados e amenizados por um mesmo sistema capitalista. Já a segunda, originada em meados de 1990, avessa a primeira, interessa-se em investigar como a modernização de sistemas políticos e econômicos bloqueia ou promove melhores resultados ecológicos.

Dentre estas abordagens e segmentação geracional, alguns autores identificam duas vertentes para a modernização ecológica: uma fraca e uma forte. A primeira agrega discussões com um caráter fechado, restrito e elitista, uma vez que está presa a realidades específicas de nações industrializadas desenvolvidas. A segunda possui pesquisas marcadas por uma qualificação multilateral, flexível e democrática, pois assume um âmbito de análise simultaneamente global e regional para as premissas da modernização ecológica.

Após a compreensão do histórico, abordagens e estruturação desta teoria foi possível esclarecer que sua proposição principal reside em viabilizar o tratamento de problemas ambientais em um contexto institucional amparado em um sistema já existente, o capitalismo. Neste, existe uma série de atores sobre os quais reside uma fonte considerável de pressões interessadas no efetivo acontecimento do desenvolvimento sustentável.

Propõe-se, portanto, que a teoria da modernização ecológica alinha a discussão da crise ambiental em um cenário capitalista livre de proposições radicais como as proferidas pelos movimentos ambientalistas revolucionárias. Neste quadro o desenvolvimento sustentável é observado como um fenômeno ocorrente por intermédio de uma cadência de ações tomadas por agentes sociais como: governos, órgãos governamentais, organizações e a própria sociedade em si (WEIDNER, 2002).

Nisto a teoria da modernização ecológica toma a frente e estabelece-se como um corpo de conhecimento que engloba o desenvolvimento sustentável. A modernização ecológica, conclui Buttel (2000), é um novo e aprimorado sinônimo para o desenvolvimento sustentável. Ela é mais viável teoricamente por apresentar uma estrutura conceitual maior e por conciliar em suas discussões problemas ambientais de indústrias transformativas instaladas em países desenvolvidos. Por fatores como este, a modernização ecológica tem se tornado atrativa como conceito de referência, justamente 
por oferecer alternativas possíveis para as conotações pessimistas levantadas sobre os níveis de poluição e crescimento econômico do sistema.

A teoria da modernização ecológica expressa uma esperança e faz isso por uma via prática, uma vez que é possível identificar e apreciar a significância das histórias de sucesso ambiental para toda a sociedade bem por isso, de acordo com Gibbs (2000) esta teoria admite que a sustentabilidade somente pode ser construída por meio de alicerces institucionais legitimados pelas sociedades. Trata-se de um fenômeno que não se baseia unicamente nos valores que precisam ser alterados em relação ao ambiente, mas também em valores e instituições que priorizam o valor do capital e a manutenção das parcerias existentes, desde que benéficas às relações sociais.

Assim como todas as teorias que procuram analisar a problemática ambiental, a teoria da modernização ecológica participa de algumas críticas, das quais a mais relevante está na constatação de que em sua constituição retórica não houve um agrupamento de considerações científicas comunais advindas de pesquisadores interessados em disseminar tal tema.

Em relação à teoria da modernização ecológica propõe-se a realização de estudos futuros que interessem em investigar quais os alicerces epistemológicos que orientam as proposições desta escola da sociologia ambiental. Apresenta-se também a idéia de realizar um levantamento de políticas brasileiras públicas e privadas orientadas ao desenvolvimento sustentável que se aliam aos preceitos da teoria da modernização ecológica.

\section{Referências}

ANDERSEN, M.S. Governance by green taxes. Manchester: Manchester Un. Press, 1994.

AYRES, R.U. Eco-restructuring. New York: United Nations Univerity Press, 1998.

BECK, U. La sociedad del riesgo. Buenos Aires: Ediciones Paidós Ibérica, 1998.

BRUNDTLAND, G.H. Our common future, World Commission on Environment and Development. Oxford: Oxford, 1987.

BUTTEL, F.H. Ecological modernization as social theory. Geoforum, Oxford, v.31, p.57-65, 2000. 
COHEN, M.J. Risk society and ecological modernisation: alternative visions for postindustrial nations. Futures, v.29, n.2, p.105-119, 1997.

DRYZEK, J. The politics of the Earth: environmental discourses. Oxford: Oxford University Press, 1997.

FOLADORI, G. As bases de comportamento humano e o ambiente. In: . Limites do desenvolvimento sustentável. São Paulo: Editora da Unicamp, 2001. p.61-82.

GIBBS, D. Ecological modernization, regional economic development and regional development agencies. Geoforum, Oxford, v.31, p.9-19, 2000.

GOLDBLATT, D. A sociedade de risco. In: . Teoria social e ambiente. Lisboa: Instituto Piaget, 1996. p.227-267.

GOULDSON, A.; MURPHY, J. Ecological modernisation: restructuring industrial economies. In: JACOBS, M. (Org.) Greening the millennium? the new politics of the environment. Oxford: Blackwell, 1997. p.74-86.

HAJER, M. Discourse coalitions and the institutionalization of practice: the case of acid rain in Great Britain. In: FISCHER, F.; FORESTER, J. (Org.). The argumentative turn in policy analysis and planning. Durham: Duke University Press, 1993.

HAJER, M. The politics of environmental discourse. New York: Oxford University Press, 1995.

HANNIGAN, J.A. Environmental sociology: a social constructionist perspective. New York: Routledge, 1995.

HARVEY, D. Justice, nature and the geography of difference. Oxford: Blackwell, 1996.

HAWKEN, P. The ecology of commerce. New York: HarperCollins, 1993.

HUBER, J. Towards industrial ecology: sustainable development as a concepto of ecological modernization. Journal of Environmental Policy \& Planning, London, v.2, p.269285.

JÄNICKE, M. Ecological modernisation: new perspectives. Journal of Cleaner Production, Amsterdam, v.22, p.557-565, 2007.

KLANDERMANS, B. The social construction of protest and multiorganization fields In: MORRIS, A.D.; MUELLER. C.M. (Org.) Frontiers in social movement theory. New Haven: Yale University Press, 1992. p.77-103.

LENZI, C.L. Sociologia ambiental: risco e sustentabilidade na modernidade. Bauru: Edusc, 2006. 
LUKE, T. Sustainable development as a power/knowledge system: the problem of 'governability'. In: FISCHER, F.; BLACK, M. (Org.) Greening environmental policy: the politics of a sustainable future. London: Paul Chapmam, 1995. p.21-32.

MARTINS, G.A.; THEÓPHILO, C.R. Metodologia da investigação científica para ciências sociais aplicadas. São Paulo: Atlas, 2007.

$\mathrm{MOL}$, A.P.J. The environmental movement in an era of ecological modernization. Geoforum, Oxford, v.31, p.45-56, 2000.

MOL, A.P.J.; SPAARGAREN, G. Environment, modernity and the risk society: the apocalyptic horizon of environmental reform. International sociology, London, v.8, p.431459, 1993.

MOL, A.P.J. The refinement of production: ecological modernization theory and the chemical industry. Utrecht: International Books, 1995.

MURPHY, R. Sociology and nature. Boulder: Westview Press, 1997.

SCHNAIBERG, A. The environment. New York: Oxford University Press, 1980.

SONNENFELD, D.A.; MOL; A.P.J. Ecological modernization, governance, and globalization. American Behavioral Scientist, Princeton, v.45, n.9, p.1456-1461, 2002.

SPAARGAREN, G.; MOL, A.P.J. Sociology, environment and modernity: ecological modernization as a theory of social change. Society and Natural Resources, London, v.5, p.323-344, 1992.

SPECTOR, M.; KITSUSE, J. Social problems: a reformulation. Social problems, New York, v.20, p.145-159, 1973.

TAYLOR, D.E. The rise of the environmental justice paradigm: injustice framing and the social construction of the environment discourses. American Behavioral Scientist, Princeton, v.43, n.4, p.508-580, 2000.

TORGERSON, D. The uncertain quest for sustainability: public discourse and the politics of environmentalism. In: FISCHER, F.; BLACK, M. (Org.) Greening environmental policy: the politics of a sustainable future. London: Paul Chapmam, 1995. p.3-20.

WEIDNER, H. Capacity building for ecological modernization: lessons from cross-national research. American Behavioral Scientist, Princeton, v.45, n.9, p.1340-1368, 2002.

YORK, R.; ROSA, E. Key challenges to ecological modernisation theory. Organization \& Environment, v.16, n.3, p.273-288, 2003. 
Recebido em: 23/05/2009

Aprovado em: 06/03/2010 